\title{
Corrosion protection of steel embedded in cement-stabilised rammed earth
}

\author{
Alexandra H. Meek ${ }^{\mathrm{a}, *}$, Christopher T.S. Beckett ${ }^{\mathrm{a}, \mathrm{b}}$, Maddalena Carsana ${ }^{\mathrm{c}}$, Daniela Ciancio ${ }^{\mathrm{a}}$ \\ ${ }^{a}$ School of Civil, Environmental and Mining Engineering, University of Western Australia, M051, 35 Stirling Highway, Crawley 6009, Western Australia, Australia \\ ${ }^{\mathrm{b}}$ School of Engineering, Institute for Infrastructure and Environment, The University of Edinburgh, Edinburgh EH93JL, Scotland, United Kingdom \\ 'Department of Chemistry, Materials and Chemical Engineering “Giulio Natta" (CMIC), Politecnico di Milano, Via Mancinelli 7, 20131 Milano, Italy
}

\section{H I G H L I G H T S}

- Cement-stabilised rammed earth protects embedded carbon steel from corrosion.

- Carbonation deteriorates the initially-passive embedded steel environment.

- Low capillary absorption and rapid desorption inhibit corrosion.

- Corrosion potential higher than $-200 \mathrm{mV}$ SCE indicates negligible corrosion.

\section{A R T I C L E I N F O}

\section{Article history:}

Received 21 November 2017

Received in revised form 23 July 2018

Accepted 26 July 2018

Available online 10 August 2018

\section{Keywords:}

Rammed earth

Cement-stabilised

Corrosion potential

Sustainable building

Carbonation

Capillary absorption

Passivation

\begin{abstract}
A B S T R A C T
Cement-stabilised rammed earth (CSRE) reinforced with steel is a modern adaptation of an ancient construction technique, permitting the use of a wider range of structural forms and applications than those used traditionally. However, corrosion behaviour of steel embedded in CSRE is not yet understood, casting doubt on the longevity of these structural solutions. In this paper, we assessed the ability of a range of CSRE mixes stabilised with $10 \%$ cement to protect embedded steel against carbonation-induced corrosion by using electrochemical measurements and considering also material alkalinity, carbonation resistance and capillary absorption. Results demonstrated that the $\mathrm{pH}$ of the CSRE mixes was sufficiently alkaline to provide the appropriate environment for passivation of steel reinforcement. Based on the experimental results, carbonation would most likely have reached the reinforcement within approximately $5-15$ years ( $50 \mathrm{~mm}$ cover) or $30-75$ years ( $150 \mathrm{~mm}$ cover), depassivating the reinforcement within the design life span. The findings demonstrated that a corrosion potential of $-200 \mathrm{mV} \mathrm{SCE}$ indicates conditions of negligible corrosion of steel in CSRE. As behaviour varied little between the four tested soil mixes (of varying granularity), it is reasonable to expect that findings presented here also apply to other soil mixes stabilised with $10 \%$ cement.
\end{abstract}

(c) 2018 Elsevier Ltd. All rights reserved.

\section{Introduction}

Rammed earth has been used in many forms throughout history, with cement-stabilised rammed earth (CSRE) being one of the more common modern variants. Steel reinforcement ("rebar") is now often specified in CSRE structures, however there is limited

Abbreviations: CL, crushed limestone; CSRE, cement-stabilised rammed earth; HCP, half-cell potential; IRA, initial rate of absorption; MDD, maximum dry density; OMC, optimum moisture content; PSD, particle size distribution; RCA, recycled concrete aggregate; SCE, saturated calomel electrode; SM1, soil mix 1; SM2, soil mix 2; UCS, unconfined compressive strength; WA, Western Australia.

* Corresponding author

E-mail address: alexandra.meek@research.uwa.edu.au (A.H. Meek). understanding of the long-term behaviour of the composite material. Having been placed in the formwork with the loose CSRE mix prior to compaction, the deformed bar becomes embedded within the material due to the compaction force during ramming. The rebar is introduced to increase tensile capacity and ductility as well as to enable roof and slab tie-downs. Despite its frequent inclusion, it is unknown whether the reinforcement is likely to corrode and either negate its addition or damage the structure in the long term. As a result, design is conservative; for example, some standards specify using expensive galvanised reinforcement to provide corrosion protection (NZS 4298:1998). While there are no reports of reinforced rammed earth structures built over the last few decades showing signs of external deterioration as a result of corrosion, it is unknown whether issues will arise in the future, i.e. whether 
corrosion is occurring and whether the wall will retain the same capacity for which it was designed.

Very limited research regarding corrosion of reinforcement in any rammed earth variants is present in the literature. CSRE has been studied here as this is the most commonly used variant of modern stabilised rammed earth in Australia. It should be noted that reinforcement is not recommended in unstabilised rammed earth due to a lack of anchorage [2]. A significant body of research regarding corrosion of reinforcement in concrete structures does however exist. Given that CSRE and concrete share a number of similarities such as components (e.g. aggregate and cement as stabiliser) and relevant properties for durability aspects (e.g. pH, density, pore structure), it is potentially reasonable to assume that the reinforcement is exposed chemically to a comparable environment in both.

The service life of a structure reinforced with steel will depend on the corrosion "initiation" and "propagation" phases [3]. In concrete, the high alkalinity of cement paste protects steel reinforcement from corrosion as a passivating layer develops on the surface of the steel. Despite providing initial protection, over time this passivating layer can deteriorate through ingress of aggressive agents such as carbon dioxide $\left(\mathrm{CO}_{2}\right)$ or chloride ions (the latter particularly in coastal areas). Carbonation, caused by the reaction of carbon dioxide $\left(\mathrm{CO}_{2}\right)$ from the air with alkaline components in the cement paste, is the most common cause of degradation in reinforced concrete. As less-alkaline calcium carbonates are formed during carbonation, $\mathrm{pH}$ of the affected cementitious material is lowered to a value around 9, depassivating the steel once the carbonation front penetrates the cover depth. The carbonation reaction depends on environmental factors (such as humidity, temperature and $\mathrm{CO}_{2}$ concentration) and material penetrability which is determined by pore network connectivity: the more pores that are connected to the outside surface, the greater the penetration. The time taken to lose the steel passivation due to carbonation is the initiation phase. Once the material is no longer protecting reinforcement from corrosion, i.e. the steel is depassivated, the propagation phase will depend on presence of moisture and oxygen on the surface of reinforcement. Capillary absorption generally controls availability of moisture in a steel reinforced material and is also the main transport mechanism controlling ingress of aggressive agents (such as chlorides).

One particular case of a reinforced CSRE wall in Perth, Western Australia (WA) was investigated by Beckett and Ciancio [4]. The wall was built around 1970 in Cottesloe, a coastal suburb of Perth. The parent sandy soil ( $<7 \%$ fines) was stabilised with $7 \%$ Portland cement by dry mass of soil. The wall comprised a $200 \mathrm{~mm}$ buried portion atop a rammed earth footing; the remainder $(\sim 1800$ $\mathrm{mm}$ ) was exposed to incident rainfall with little or no surface protection. The wall was demolished in 2012 and sections showing no surface damage were extracted for analysis. Investigations revealed that the uncoated mild steel reinforcement was highly corroded in the $200 \mathrm{~mm}$ buried region between the footing and exposed wall surface, due to groundwater ingress, whilst the remainder was in as good a condition as when it was first installed (Fig. 1). Although an extreme case, being an external wall with no roof protection and in a coastal environment, this example highlights that extensive damage is possible without necessarily being revealed by the state of the wall's surface.

This casts doubt on the effectiveness of steel reinforcement in existing rammed earth structures and the design life and/or safety of these structures. It also calls into question whether it is worth specifying steel reinforcement in rammed earth structures if its longevity cannot be guaranteed. Therefore, in order to provide some certainty for reinforced rammed earth design, it is essential to understand whether the rammed earth can provide adequate protection for steel reinforcement against carbonation-induced corrosion: the subject of our paper.

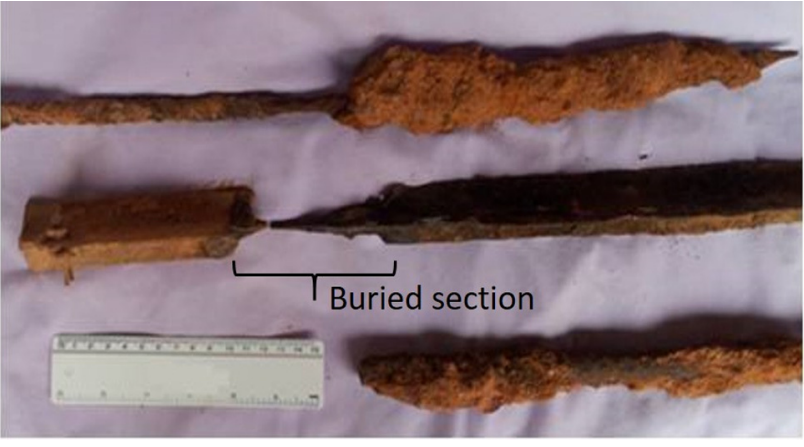

Fig. 1. Corroded reinforcement from 30-year-old CSRE wall.

Firstly, carbonation resistance and capillary absorption of different CSRE mixes were measured as these material properties strongly influence corrosion protection. Subsequently, the $\mathrm{CO}_{2}-$ induced corrosion behaviour of carbon steel bars embedded in the different CSRE mixes studied in this work when exposed to various environments was compared. Based on material properties and corrosion behaviour, an assessment is made of whether corrosion may impact the service life of the material. In the absence of specific CSRE tests, existing concrete and masonry testing was used: the appropriateness of these tests for CSRE was also assessed.

\section{Experimental program}

\subsection{Materials and characterisation}

It is well-established from cementitious materials research that the ability of both air- and water-borne aggressors to penetrate a material is dependent on both pore volume and geometry [5]. A number of properties affect CSRE pore structure, such as specific surface area of the soil(s), density of the rammed earth, compaction conditions (water content and density) and stabiliser hydration [6]. This study therefore used four different rammed earth mixes stabilised with cement (see Table 1) and typical of construction around the world to evaluate their influence on the corrosion behaviour of carbon steel in CSRE, as well as to facilitate correlations between durability performance and soil mix characteristics.

The four base soils used were crushed limestone $(\mathrm{CL})$, recycled concrete aggregate (RCA), a natural soil from the Dampier Peninsula, WA (Soil mix 1, SM1) and a blend of crushed limestone and kaolin clay (SM2). Particle size distributions of base soils (PSD; according to AS 1289.3.6.1-2009 [7]) are shown in Fig. 2. United soil classification system designation of each base soil is included in Table 1.

- CL was selected as this is commonly used in WA as the 'earth' component of rammed earth in preference to the local soil. It is inert and generally well-graded, with subrounded particles. It is a readily available quarried material in WA.

- RCA is a popular soil substitute in WA for CSRE construction due to its environmentally-friendly properties as a waste material [8]. The soil classification of RCA differs significantly to that of the other soils used; it is poorly graded with angular particles, a far greater proportion of crushed rock $(\sim 50 \%>4.75 \mathrm{~mm})$ and minimal fine to medium sized materials (Fig. 2).

Being a waste material, each RCA mix may differ in terms of characteristics such as mineralogy, angularity and PSD, depending on the original concrete product and level of processing. Furthermore, RCA may include some unhydrated cement particles from the manufacture of the concrete for its initial use; the presence of unhydrated cement was not considered to impinge on testing presented here. 
Table 1

Summary of CSRE mix preparation details and properties.

\begin{tabular}{|c|c|c|c|c|c|c|c|c|}
\hline \multirow{2}{*}{$\begin{array}{l}\text { CSRE mix: } \\
\text { Base soil + } 10 \% \\
\text { cement }\end{array}$} & \multirow[t]{2}{*}{$\begin{array}{l}\text { Base soil (United soil classification } \\
\text { system designation) }\end{array}$} & \multirow[t]{2}{*}{$\operatorname{MDD}\left(\mathrm{kg} / \mathrm{m}^{3}\right)$} & \multirow[t]{2}{*}{ OMC (\%) } & \multirow[t]{2}{*}{ UCS avg (MPa) } & \multicolumn{2}{|l|}{$\mathrm{pH}$} & \multicolumn{2}{|c|}{$\begin{array}{l}\text { Available pore } \\
\text { volume (\%) }\end{array}$} \\
\hline & & & & & Manufacture & After curing & @5 wks & @30 wks \\
\hline $\mathrm{CL}$ & Crushed limestone (SW) & 1950 & 12 & 14.0 & 12.0 & 13.0 & 17.1 & 15.7 \\
\hline RCA & Recycled concrete aggregate (GP) & 1995 & 13 & 8.9 & 11.6 & 12.9 & 19.4 & 17.2 \\
\hline SM1 & Dampier Peninsula natural soil (SP) & 2040 & 9 & 12.9 & 11.9 & 12.9 & 14.3 & 12.6 \\
\hline SM2 & $85 \%$ Crushed limestone $+15 \%$ kaolin clay (SC) & 2075 & 11 & 10.0 & 11.7 & 12.7 & 18.5 & 16.8 \\
\hline
\end{tabular}

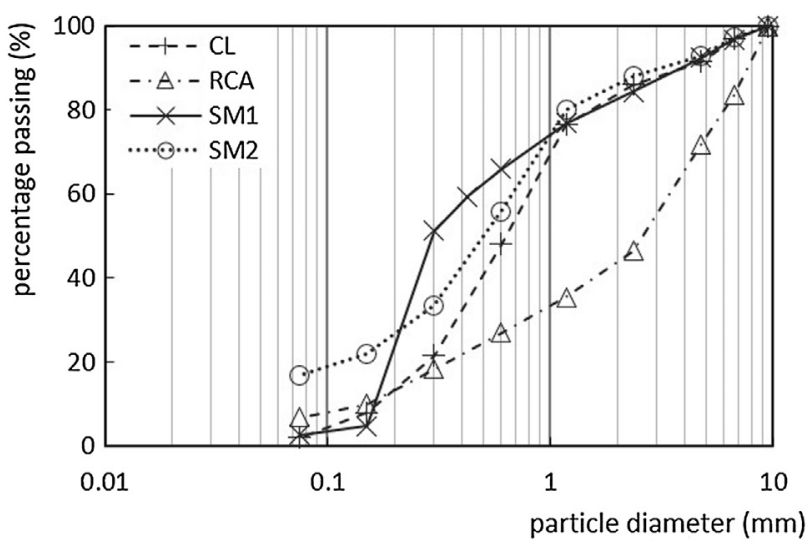

Fig. 2. Dry PSD of each base soil (refer Table 1).

- Soil mix 1 (SM1) largely consisted of fine sand with little gravel, coarse sand or fines. This was selected to broaden the range of soils being used as, like RCA, it was poorly graded but with disparate predominant particle sizing.

- An "engineered" (i.e. artificial) soil mix, referred to as Soil mix 2 (SM2), was created from a blend of $85 \%$ CL and $15 \%$ kaolin clay. The kaolin used was an anhydrous aluminium silicate (PL 27\%, LL 61\%; [9]). Addition of kaolin increased the fines content (Fig. 2), intended to modify the CL pore structure. As both components of SM2 were commercially available, mix mineralogy and grading was highly repeatable.

All soils were stabilised with $10 \%$ cement (relative to dry soil mass) as this is common practise around the world [10].

All specimens were manufactured at optimum moisture content (OMC) and maximum dry density (MDD). These parameters were established for each soil mix in accordance with AS 1289.5.2.1-2003 [11] using a modified compactive effort, selected as it produced densities similar to those used in the field (obtained using pneumatic rammers) [12]. As stabilisers had been added, each test was completed within $45 \mathrm{~min}$ of adding water to ensure adequate workability and accuracy of results prior to stabiliser hydration [1]. Specimen dry density was measured throughout testing to track variation.

UCS testing was completed as a quality control measure to ensure each CSRE mix was representative of those suitable for RE construction. Testing was carried out as per AS 5101.4-2008 [13]. Specimens were manufactured by combining adequate base soil and $10 \%$ anhydrous stabiliser to form a homogenous mix. Base soils were sieved prior to mixing, using only the material passing the $9.5 \mathrm{~mm}$ sieve to ensure diameter of any aggregates was less than ten times the minimum mould diameter. Water was then added to meet OMC for each mix. As for compaction testing, specimen preparation was completed within 45 min of stabiliser addition. Specimens were compacted in five layers in a mould of height
$200 \mathrm{~mm}$, diameter $104 \mathrm{~mm}$. To ensure MDD was met, soil mass for one layer was calculated and compacted to a depth of $40 \mathrm{~mm}$ using a volume-controlled rammer head. Four specimens of each mix were manufactured with the exception of SM1 (one specimen due to insufficient material). Results for each mix, tested after 28 days' curing in a humidity-controlled room $(94 \pm 2 \%$ relative humidity, $21 \pm 1^{\circ}$ temperature), are given in Table 1 . Results showed that all soil mixes would be suitable for low-rise rammed earth building per NZS 4298:1998 [1] requirements of greater than 1.3 MPa (7-16 MPa; averages shown in Table 1).

Specimen $\mathrm{pH}$ and available pore volume (apparent porosity) were examined to support the study of corrosion behaviour. The $\mathrm{pH}$ of each stabilised CSRE mix was tested at manufacture as per the Eades and Grim procedure [14] to verify that CSRE was sufficiently alkaline to promote passivation. $\mathrm{pH}$ was tested again following the curing phase (see Table 1) to view any possible evolution.

Available pore volume of each specimen type was evaluated using an immersed absorption test, measured at 5 weeks from manufacture and at 30 weeks. A specimen of each CSRE mix was immersed in water and weighed at fixed time intervals until constant mass was reached. Available pore volume was then calculated as:

$p=\left\{\frac{\left(m_{s}-m_{d}\right)}{\delta_{w}}\left(\frac{1}{V_{s p}}\right)\right\} 100$

where $m_{s}$ and $m_{d}$ are respectively saturated (s) and oven dry $(d)$ specimen masses $(m)(\mathrm{kg}), \delta_{w}$ is density of water $\left(\mathrm{kg} / \mathrm{m}^{3}\right)$ and $V_{s p}$ is volume of the specimen $\left(\mathrm{m}^{3}\right)$. Calculated available pore volume for each CSRE mix is also given in Table 1.

No tests to investigate corrosion susceptibility exist specifically for CSRE. In this work, it was assumed that tests developed for durability-related properties in concrete could be adapted to suit CSRE; the success of this assumption is discussed later in this paper.

\subsection{Carbonation resistance}

For concrete, the rate at which the carbonation front develops can generally be described by

$d=k t^{1 / n}$

where $k$ is the carbonation coefficient and $t$ is time (years) [3]. $k$ $\left(\mathrm{mm} /\right.$ year $\left.^{1 / \mathrm{n}}\right)$ can be calculated for a given material to specify cover depth for protection of reinforcement from carbonation-induced corrosion for the life of the structure.

$100 \mathrm{~mm}$ cube specimens of the four CSRE mixes were manufactured for carbonation testing. These were compacted in two 50 mm layers of known mass compacted to the target density using a jackhammer and a volume-controlled rammer head. Compacted surfaces were scarified to promote amalgamation of the two layers. Each was weighed and then cured for 28 days at a high humidity to 
provide an appropriate environment for cement hydration (in accordance with AS 5101.4-2008 [13]).

Carbonation testing was carried out across a six-month period to assess whether the relationship which described $\mathrm{CO}_{2}$ penetration with time in concrete might be applied to those CSRE mixes studied in order to determine their carbonation coefficients (Table 2). Testing was undertaken after 14 days (half-curing period), 5 weeks, 15 weeks and 30 weeks from manufacture. Excepting those tested at 14 days, specimens were removed from the curing room after 28 days and exposed to ambient air conditions. Testing at 5 weeks was carried out to allow a week for the specimens to equilibrate to the ambient environment: the lower humidity with respect to the curing room progressively reduces the water in the pores thereby favouring access to $\mathrm{CO}_{2}$. Air temperature throughout the experimental program varied between $11.7^{\circ} \mathrm{C}$ and $25.1^{\circ} \mathrm{C}$ with an average of $18.2^{\circ} \mathrm{C}$. Relative humidity varied between $43.3 \%$ and $83.9 \%$ with an average of $63.2 \%$.

Specimens were tested by breaking them in half along the ramming line, using compressed air to remove any detached particles (to ensure no cross-contamination between carbonated and uncarbonated areas). In order to evaluate carbonation depth by colorimetric test, each broken face of the specimen was then sprayed with a $1 \%$ alcoholic solution of phenolphthalein as per I.S. EN 13295:2004 [15]. The $\mathrm{pH}$ indicator is colourless in areas where material is carbonated $(\mathrm{pH} \leq 9)$ and magenta where there is alkaline reserve. Measurements for carbonation progression were taken on four sides of each specimen and averaged. Specimens were exposed to atmospheric $\mathrm{CO}_{2}$ only, rather than an accelerated $\mathrm{CO}_{2}$ environment, to be more representative of likely site conditions.

Additional SM2 carbonation specimens were manufactured to a lower density of $1800 \mathrm{~kg} / \mathrm{m}^{3}$ at a water content of $10 \%$ to examine the effect of reduced density on carbonation performance. Besides that, specimen components, preparation and exposure conditions were identical to those described above.

\subsection{Initial rate of absorption (IRA)}

Initial rate of absorption (IRA) is a measure of the ease of ingress of water, and therefore any water-borne aggressors, under atmospheric conditions. Although developed for masonry and concrete, Hall and Djerbib [16] showed that these methods can be extended to CSRE.
$100 \mathrm{~mm} \times 100 \mathrm{~mm} \times 50 \mathrm{~mm}$ specimens were manufactured for IRA testing. These specimens comprised a single rammed layer but were otherwise identical to carbonation specimens. IRA testing was undertaken at 5 weeks ( 4 weeks' curing, 1 week ambient), 15 weeks and 30 weeks from manufacture (Table 2). Testing was carried out according to AS/NZS 4456.17:2003 [17] with slight variations for rammed earth as described by Hall and Djerbib [18]. Specimens were placed on a wick of florists' foam $(80 \mathrm{~mm}$ dia.; a material with negligible capillary resistance) in water. That the contact area with florists' foam was smaller than the specimen face allowed for a more realistic 3D water uptake. Specimens were weighed each minute to $0.01 \mathrm{~g}$ for five minutes, then at ten minutes, followed by ten-minute intervals up to $60 \mathrm{~min}$.

Testing reported by Ciancio et al. [19] indicated that exposure to high temperatures during oven drying accelerates stabiliser hydration. Therefore, specimens were not oven dried prior to IRA testing but were tested from equilibrium at ambient conditions to avoid alteration to material behaviour. Testing from ambient lab conditions meant that these measurements may be more representative of possible exposure conditions.

\subsection{Half-cell potential (HCP)}

Half-cell potential (HCP) testing is one of several electrochemical techniques that exist for monitoring and assessing corrosion in reinforced concrete. This non-destructive test can be used either in situ or in a lab environment. HCP was used in this study to measure corrosion potential of steel embedded in the various CSRE mixes in a number of different environments. This test was completed in accordance with ASTM C876-91 [20] using a calomel reference electrode (SCE) placed on the concrete surface. As well as the steel bar, specimens were also instrumented with an internal electrode of activated titanium which can be used as an alternative to the SCE electrode (measurements made versus activated titanium are not reported in this paper). Potential readings were taken with a high-impedance voltmeter. A schematic of an instrumented specimen is shown in Fig. 3.

Two $100 \mathrm{~mm}$ cube specimens were made for HCP testing per soil mix (excepting SM1, for which only one was prepared due to a lack of material) in a similar manner to carbonation specimens. In addition to the carbonation specimen manufacturing process described in Section 2.3, a titanium reference electrode and $90 \mathrm{~mm}$ length of reinforcement were embedded between the two

Table 2

Summary of specimens for each test.

\begin{tabular}{|c|c|c|c|c|c|c|c|c|c|c|c|c|c|c|}
\hline \multirow[t]{3}{*}{ Soil } & \multirow[t]{3}{*}{ Test } & \multicolumn{13}{|c|}{ Age of specimen (weeks from manufacture) } \\
\hline & & \multicolumn{13}{|c|}{ No. specimens tested } \\
\hline & & 2 & 4 & 5 & 7 & 8 & 11 & 15 & 20 & 25 & 30 & 44 & 47 & 52 \\
\hline \multirow[t]{3}{*}{ CL } & Carbonation & 1 & & 1 & & & & 1 & & & 1 & & & $1^{1}$ \\
\hline & IRA & 2 & & 5 & & & & 3 & & & 5 & & & \\
\hline & HCP dry \& immersed unless noted otherwise (UNO) & & & 2 & & 2 & 2 & 2 & 2 & $2,2^{2}$ & $2^{3}$ & $2^{4}$ & 2 & \\
\hline \multirow[t]{3}{*}{$\mathrm{RCA}$} & Carbonation & 1 & & 1 & & & & 1 & & & 1 & & & $1^{1}$ \\
\hline & IRA & & & 5 & & & & 3 & & & 5 & & & \\
\hline & HCP dry \& immersed UNO & & & 2 & & 2 & 2 & 2 & 2 & $2,2^{2}$ & $2^{3}$ & $2^{4}$ & 2 & \\
\hline \multirow[t]{3}{*}{ SM1 } & Carbonation & 1 & & 1 & & & & 1 & & & 1 & & & $1^{1}$ \\
\hline & IRA & & & 5 & & & & 3 & & & 5 & & & \\
\hline & HCP dry \& immersed UNO & & & 1 & & 1 & 1 & 1 & 1 & $1,1^{2}$ & $1^{3}$ & $1^{4}$ & 1 & \\
\hline \multirow[t]{4}{*}{ SM2 } & Carbonation (MDD) & 1 & & 1 & & & & 1 & & & 1 & & & $1^{1}$ \\
\hline & Carbonation (low density) & & 1 & 1 & 1 & & 1 & & & & & & & \\
\hline & IRA & & & 5 & & & & 3 & & & 5 & & & \\
\hline & HCP dry \& immersed UNO & & & 2 & & 2 & 2 & 2 & 2 & $2,2^{2}$ & $2^{3}$ & $2^{4}$ & 2 & \\
\hline
\end{tabular}

\footnotetext{
1 HCP specimen.

2 Immersion followed by drying.

${ }^{3}$ Humidity room.

${ }^{4}$ Rainfall simulation.
} 

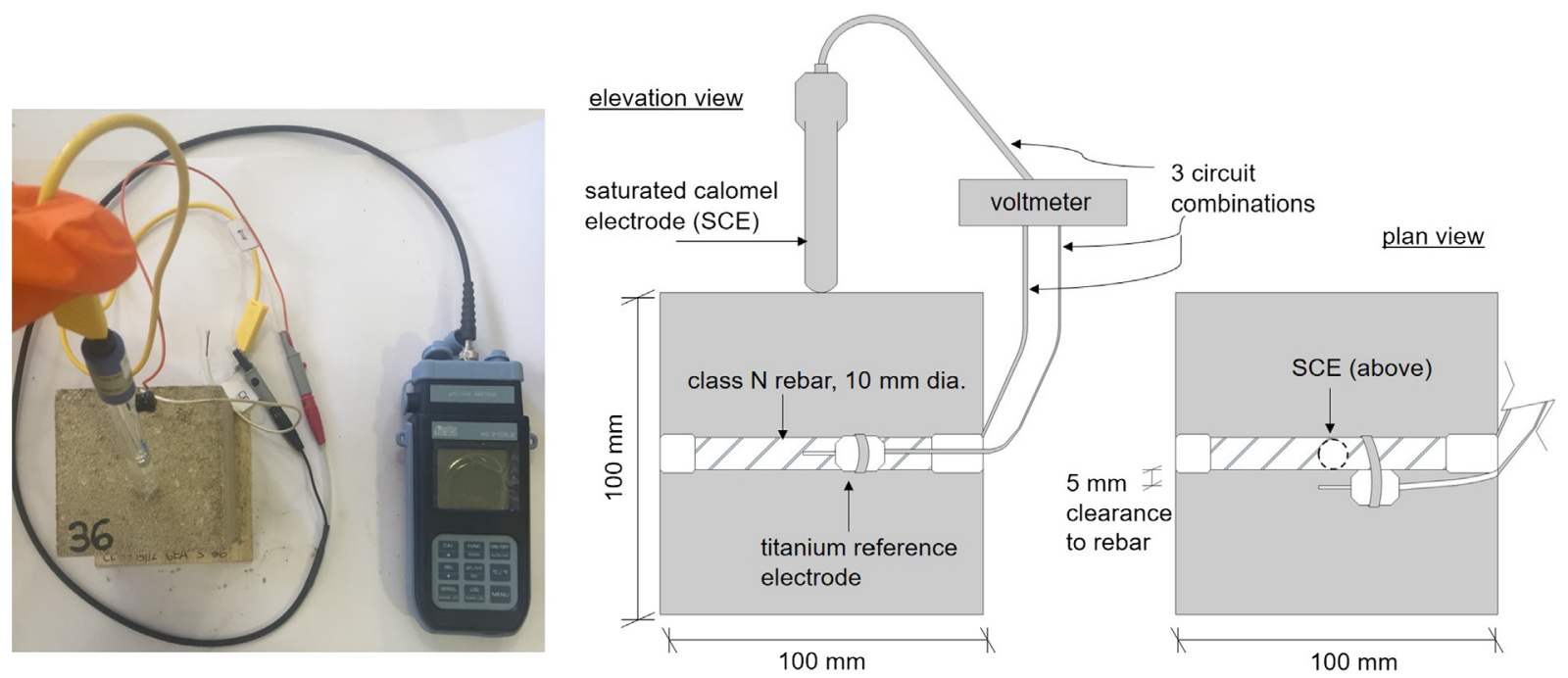

Fig. 3. HCP test set-up (photo courtesy of G. Orfeo).

compacted layers as shown in Fig. 3. Cables to complete the HCP circuit exited each specimen at the interface of the two layers.

Class $\mathrm{N}, 500 \mathrm{MPa}$, deformed bar reinforcement (10 $\mathrm{mm}$ dia.) was used as this is commonly used for CSRE reinforcement in Australia. Bars were sandblasted to be free of oxides prior to specimen manufacture. Bar ends were covered with thermal tape to leave an exposed length of $80 \mathrm{~mm}$ within each specimen whilst avoiding corrosion on the bar ends (as shown in Fig. 3). A number of studies $[21,22]$ found that HCP can vary significantly as a function of exposure conditions and have suggested that an individual HCP measurement cannot be taken to indicate corrosion state of embedded reinforcement but that, when used as a comparative measure (e.g. between different areas of a structure exposed to the same conditions), corroding areas can be found through potential mapping. In the same way, results in this study will give indications of whether the various rammed earth mixes provide a better or worse environment for steel reinforcement when compared with one another, given equivalent exposure conditions, type of steel reinforcement and experimental specimen. For the same reason, it is recommended to be used in combination with other methods and/or destructive testing to confirm results [20]. Following completion of corrosion testing, reinforced specimens used in this experimental work were split in half to allow a visual assessment of the corrosion state to compare to the HCP readings.

An initial HCP test was carried out immediately after the curing phase (i.e. on reinforced CSRE specimens maintaining equilibration to high humidity conditions). Specimens were then air dried until reaching constant mass in ambient conditions, after which testing was repeated approximately once per month over a six-month period and then again at 11 and 12 months from manufacture. Each test consisted of one reading on the reinforced specimens while they were exposed to dry conditions followed by readings taken after 1, 3, 8 and $24 \mathrm{~h}$ while the specimens were immersed in water.

To evaluate differences in terms of corrosion behaviour of steel in CSRE when exposed to laboratory condition and high humidity environments, at 30 weeks from manufacture, reinforced specimens were placed in the humidity room and their corrosion potential and mass tested periodically until reaching equilibrium (Table 2). They were then returned to ambient laboratory conditions.

To study corrosion behaviour during desorption, specimens remained immersed until reaching constant mass and were then left in ambient conditions to dry. Mass and HCP were measured throughout the exposure period to determine how quickly the material re-equilibrated on emergence and to assess changes in corrosion behaviour both during extended immersion and desorption. Alternative wetting and drying cycles provided the worst-case environment for steel in rammed earth in case of risk of carbonation-induced corrosion. HCP was also carried out on reinforced specimens with only one face exposed to water to understand corrosion behaviour in more realistic conditions (representative of incident rainfall, Table 2). Test setup followed the same configuration as for IRA testing but with a controlled volume of water applied. A volume of water corresponding to the daily rainfall in the Perth region over a two week period during July 2016 (wettest fortnight of 2016 [23]) was placed in a covered tray with each specimen enabling each to absorb the full amount over $24 \mathrm{~h}$. In reality, it is likely significant surface runoff would occur from a (typically vertical) rammed earth surface whereas in this test, specimens had unlimited exposure to the simulated rainfall volume. Although extreme, it is nevertheless a potentially morerealistic scenario for corrosion likelihood than full immersion.

Quantitative information on the corrosion state of steel in cementitious materials can be obtained by considering also other electrochemical techniques in addition to its corrosion potential (such as the measurement of corrosion rate estimated by polarization resistance). For steel reinforcement in concrete, a corrosion rate of $1 \mathrm{~mA} / \mathrm{m}^{2}$ (an approximate thickness reduction of $1.17 \mu \mathrm{m} /$ year) is the limit below which corrosion is considered negligible (e.g. [5,24]). A previous preliminary CSRE corrosion study (carried out at the Department of Chemistry, Materials and Chemical Engineering of Politecnico di Milano by the authors) found a correlation between corrosion potential and corrosion rate of steel embedded in CSRE: a negligible corrosion rate of $1 \mathrm{~mA} / \mathrm{m}^{2}$ corresponded to approximately $-200 \mathrm{mV} \mathrm{SCE}$ [25]. Measures of corrosion potential of the steel bar versus calomel electrode obtained in the CSRE mixes studied in this research when exposed to different conditions were compared both with this CSRE specific value $(-200$ $\mathrm{mV}$ SCE) and with those found for concrete, given in ASTM C87691 [20] (see Table 3, taking into account that indicative potentials have been converted from a Copper/Copper Sulfate electrode [CSE] to a Saturated Calomel [SCE] electrode).

Potential differences were assessed for three circuit combinations: between the (i) reinforcing bar and the calomel electrode; (ii) between the bar and the internal titanium electrode; and (iii) between the titanium electrode and the calomel electrode. 
Table 3

Indicative potential brackets for likelihood of corrosion

\begin{tabular}{|c|c|}
\hline $\begin{array}{l}\text { Corrosion potential } \mathrm{E}_{\text {corr }}(\mathrm{mV} \text {, } \\
\text { converted from CSE to SCE) }\end{array}$ & Likelihood of corrosion \\
\hline $\mathrm{E}_{\text {corr }}>-200 \mathrm{mV}$ & $\begin{array}{l}\text { Specific potential criteria for corrosion of } \\
\text { reinforced CSRE [25] }\end{array}$ \\
\hline $\mathrm{E}_{\text {corr }}>-125 \mathrm{mV}$ & $\begin{array}{l}\text { Corrosion conditions }<10 \% \text { probability at } \\
\text { time of measurement }[20]\end{array}$ \\
\hline$-275 \mathrm{mV}<\mathrm{E}_{\text {corr }}<-125 \mathrm{mV}$ & Unknown probability [20] \\
\hline $\mathrm{E}_{\text {corr }}<-275 \mathrm{mV}$ & Corrosive conditions $>90 \%$ probability [20] \\
\hline
\end{tabular}

Following corrosion potential testing, carbonation depth of HCP specimens was also measured at 12 months from manufacture as described in the previous sections.

Throughout exposure to all environments, mass of specimens was measured concurrently with all HCP measurements to enable any potential correlation between corrosion potential and moisture content above equilibrium. Following all other testing at the various specimen ages, specimens were oven dried, giving absolute moisture content as per AS 1289.5.2.1-2003 [11].

A summary of all tests, the number of specimens and test times is provided in Table 2. Specimen numbers for each test were selected to give an accurate representation of material behaviour whilst keeping overall specimen numbers to a reasonable level.

\section{Results and discussion}

\subsection{Carbonation}

Carbonation depths with time are shown in Fig. 4. At manufacture, specimens present the highest point of water content, rendering the carbonation rate negligible. As water content reduced, carbonation commenced. Initial carbonation rate was highest for CL. In agreement, CL also had the most significant water content reduction in the first two weeks; carbonation can only commence once $\mathrm{CO}_{2}$ can penetrate the pore network.

Carbonation was measured over 30 weeks to determine progression rates. Carbonation rates ranged between 8 and $16 \mathrm{~mm} /$ year $^{0.67}$, for the different CSRE mixes, calculated as:

$k=\frac{d}{t^{1 / n}}$

where $k$ is carbonation coefficient, $d$ is depth of cover ( $\mathrm{mm}$ ) minus $5 \mathrm{~mm}$ (Yoon et al. [26] showed that material is no longer protected from corrosion if the carbonation front closes to within $5 \mathrm{~mm}$ of the reinforcement) and $t$ is time (years) (e.g. [3]). Curing time was disregarded in calculation of carbonation rates as results in Fig. 4 suggest that carbonation progresses only after equilibrium with ambient conditions has been reached. The relationship given in Equation (3) assumes that the $\mathrm{CO}_{2}$ concentration is constant. In reality, the rate of carbonation over time will depend on environmental factors (such as temperature, humidity and $\mathrm{CO}_{2}$ concentration) and factors related to cementitious materials (mainly alkalinity and permeability). The exponent $n$ is often approximately equal to two for ordinary concrete but may be greater than two for dense concrete [5]. This study found an exponent of $n=1.5$ to be a better fit for the tested CSRE. This indicates that, although the established concrete testing methods are valid, the CSRE carbonation depth versus time relationship is faster than in concrete. In particular, the carbonation rate was lower for CSRE mixes made with SM1 and SM2 soils than those with RCA and CL.

Table 4 shows time until an indicative cover depth would be breached, calculated using Eq. (3) extrapolated over the depth of interest. For typical cover depths, carbonation was estimated to reach the reinforcement within the design life span (50 years). Historically, rammed earth walls were commonly $>300 \mathrm{~mm}$ thick. With central reinforcement, time to breach such cover may exceed the design life dependent on mix characteristics. Modern rammed earth structures however are more frequently being built as insulated panels (e.g. [27]) which significantly reduces the cover to reinforcement.

A general relationship between available pore volume and carbonation rate for CSRE could not be established due to other uncontrolled variables associated with the soil types (e.g. soil specific surface area, grading, angularity, mineralogy). However, a relationship between carbonation rate and density was evident when contrasting specimens of a given soil type, as shown in Fig. 5 (only SM2 shown for clarity as other CSRE mixes behaved similarly): lower density specimens carbonated at a faster rate due to the increased ease of $\mathrm{CO}_{2}$ penetration. For results shown in Fig. 5, carbonation rate of the low-density specimens was $28.5 \mathrm{~mm} /$ year $^{0.67}$, approximately three times faster than specimens compacted to MDD (9.1 mm/year $\left.{ }^{0.67}\right)$. Given that final $\mathrm{RE}$ density on site is controlled largely by operator experience,

Table 4

Years to carbonation front breaching illustrative cover depths.

\begin{tabular}{lllll}
\hline \multirow{2}{*}{ Cover $(\mathrm{mm})$} & \multicolumn{4}{l}{ Time to carbonation breach of cover (years) } \\
\cline { 2 - 5 } & CL & RCA & SM1 & SM2 \\
\hline 50 & 4.9 & 9.3 & 12.7 & 11.0 \\
150 & 28.6 & 53.6 & 73.2 & 63.5 \\
\hline
\end{tabular}

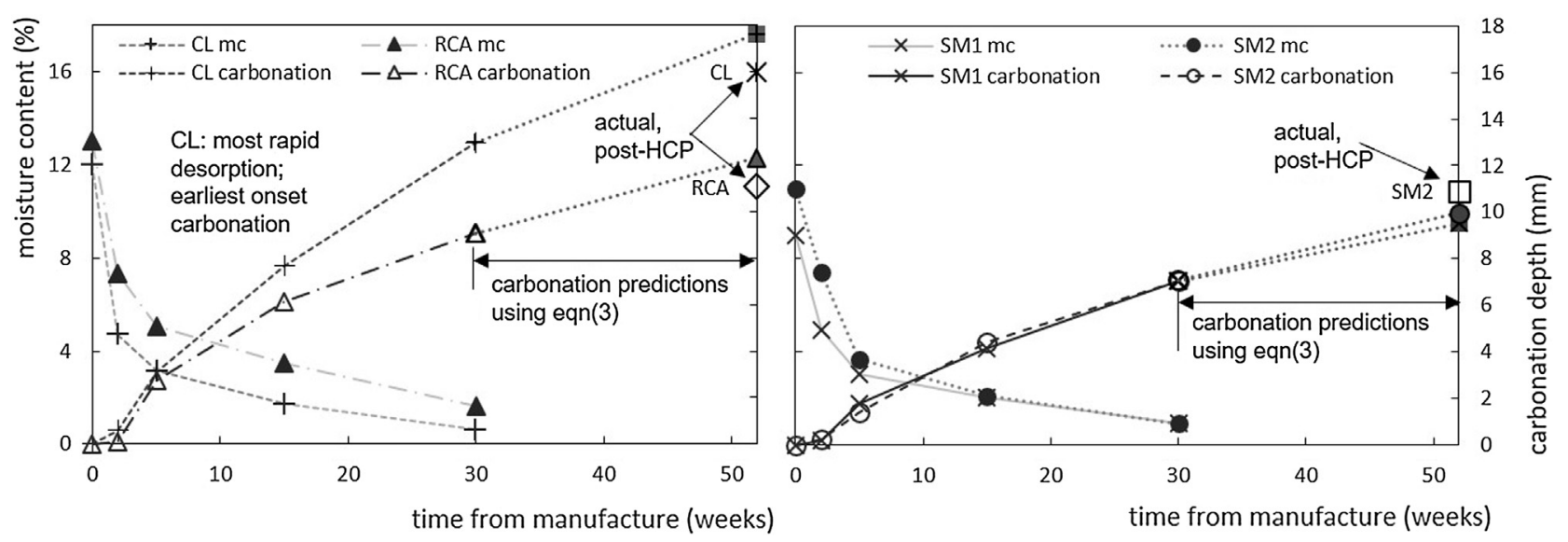

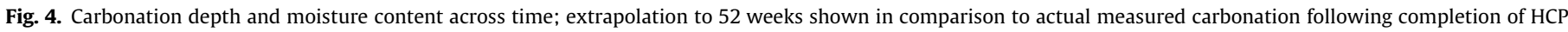
testing (CL, RCA, SM2). 


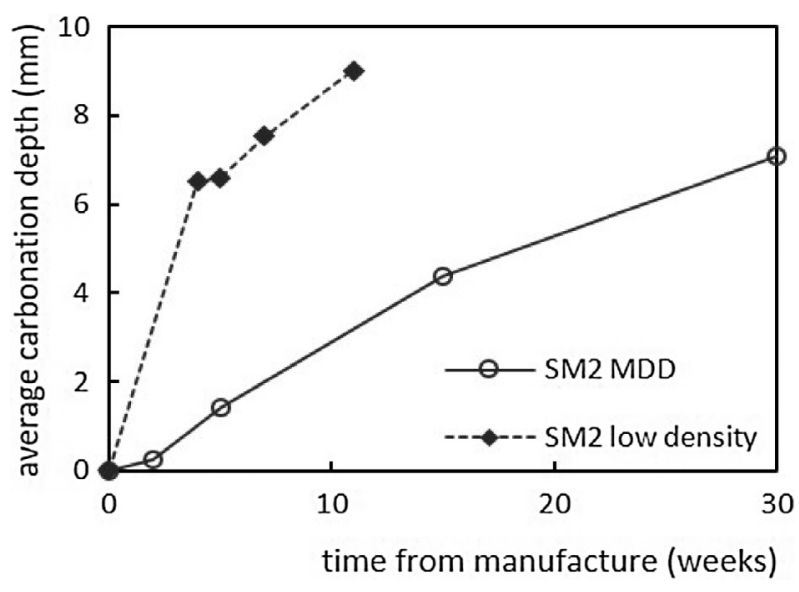

Fig. 5. Carbonation depth comparison of SM2 low density and MDD specimens.

consequences of poor density control should be considered when designing CSRE reinforcement.

\subsubsection{Carbonation depth following HCP tests}

Twelve months after manufacture, final carbonation measurements were taken on selected HCP specimens. Fig. 4 shows measured data to 30 weeks followed by both the predicted extrapolation to 52 weeks using Eq. (3) and actual carbonation measurements of HCP specimens. Despite approximate monthly wetting during HCP testing, carbonation progressed similarly to relationships found using carbonation-specific specimens. Such a result indicates that the periodic wetting cycles were insufficient to stall carbonation for any significant time: specimens were able to desaturate sufficiently rapidly for $\mathrm{CO}_{2}$ to continue penetrating the material. As such, it would not be expected that incident rainfall would slow the penetration of carbonation in a CSRE structure. Given that specimen carbonation rates in the curing room were low, it may be that exposing HCP specimens to higher humidity conditions would have affected carbonation rate. However, as such a process was not representative of the outside environment, this was not investigated.

\subsection{Capillary absorption}

Initial rate of surface absorption of the four tested soil mixes is shown in Fig. 6 (5-week specimens only for clarity), presented as the mass of water absorbed per unit surface area per minute. Results for porous materials investigated by previous authors are also shown for comparison. Absorption in porous materials has previously been demonstrated to be linear with respect to the square root of time, according to

$i=S \sqrt{t}$

where $i$ is the cumulative absorption $\left(\mathrm{kg} / \mathrm{m}^{2}\right), S$ the sorptivity $(\mathrm{kg} /$ $\mathrm{m}^{2}$.min) and $t$ the time (minutes) (e.g. $[5,18]$ ). As shown in Fig. 7 , this relationship adequately described CSRE specimen absorption in this study.

As shown in Fig. 4, specimen water contents roughly halved over the testing period. However, no significant change in absorptivity was found between specimens of various ages $-5,15$ and 30 weeks - suggesting that water content changes were not sufficiently extreme to appreciatively affect capillary forces. 5-week specimens were therefore suitable to indicate long-term CSRE absorptivity.

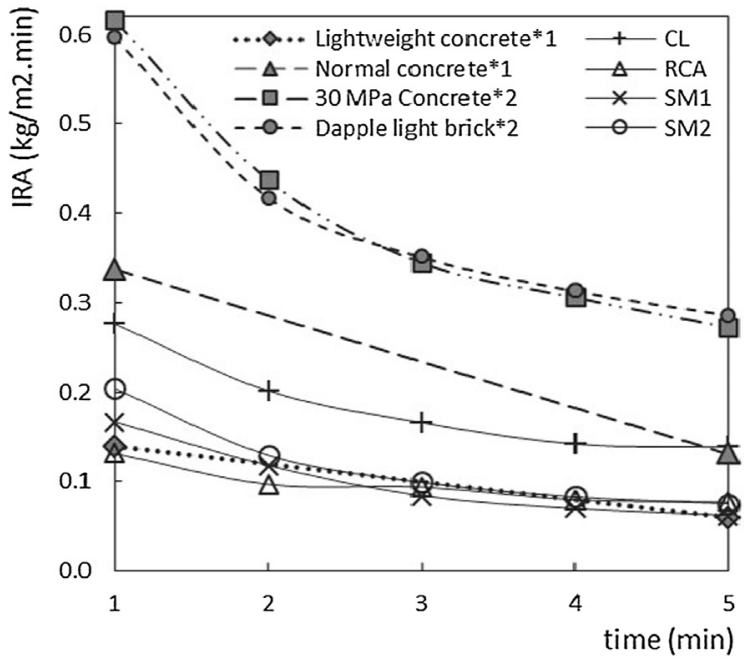

Fig. 6. Initial rate of absorption over $5 \mathrm{~min}$; CSRE and comparative materials $\left({ }^{1}[28]\right.$; $\left.{ }^{2}[18]\right)$.

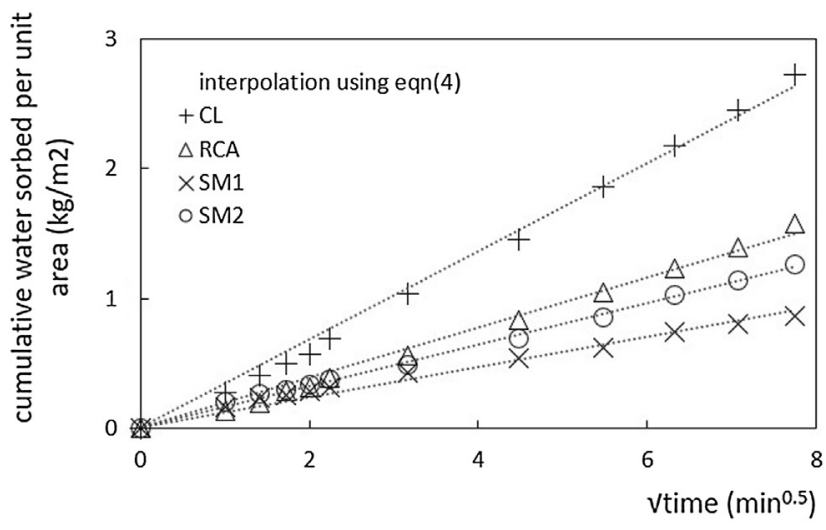

Fig. 7. Water sorption over $60 \mathrm{~min}$; CSRE (5 weeks from manufacture).

CSRE specimens consistently showed lower IRA and cumulative sorption values than materials tested by Hall and Djerbib [18]. However, specimens in that work were oven-dried (at $105^{\circ} \mathrm{C}$ ) prior to testing. It is well known that increased temperatures impart greater suction to the pore structure, i.e. capillary forces are higher; that our specimens achieved lower IRA and cumulative sorption values was therefore expected. Sorption values presented in Figs. 6 and 7 are therefore suggestibly more indicative of "real-world" values expected for CSRE materials exposed to water ingress.

It is anecdotally believed that rammed earth materials are particularly susceptible to moisture ingress (e.g. [29]); contrariwise, Fig. 6 shows that realistic CSRE sorption rates are comparatively low with respect to other construction materials considered. The absorption parameter cannot, however, be used as an absolute measure of quality of alternative construction materials but can be useful for comparing the different mixtures of CSRE made in this study at equal water/cement ratio and compaction method. As aggressive ions such as chlorides move most effectively in pore water by diffusion, low sorption rates could improve chloride resistance. However, since chloride penetration in cementitious materials also depends on other factors (e.g. cement content), it's not possible to draw conclusions on chloride resistance based only on the results obtained in terms of capillary measurements. A more detailed future study specifically addressing chloride resistance of CSRE would be worthwhile. 


\subsection{Corrosion potential}

When CSRE is reinforced with steel bars, the protection of embedded steel can be studied by monitoring its corrosion potential in different exposure conditions.

\subsubsection{Twelve-month dry (ambient laboratory) and immersed $\mathrm{HCP}$ testing}

Fig. 8 shows the results of electrochemical monitoring of corrosion potential of steel embedded in CSRE specimens of the various mixes (measured using saturated calomel electrode, 'SCE' noted after unit). Measurements of corrosion potential carried out while specimens were dry are reported, as are measurements following 1-h of immersion. Except for the first measurement, made 5 weeks from manufacture, at which time specimens were still drying (corrosion potential values around $-100 \mathrm{mV} \mathrm{SCE}$ ), corrosion potential in dry conditions reached positive values ranging between +100 and $+250 \mathrm{mV}$ SCE confirming steel was in a passive state. A similar but less pronounced pattern was also found for the measurements repeated monthly on the same reinforced specimens after immersion in tap water for one hour; for these specimens, corrosion potential reached stable, but more negative, values than those in dry conditions. For CSRE immersion in tap water, the diminished supply of oxygen to the steel surface brought the potential down to values around $-100 \mathrm{mV}$ SCE but still above the corrosion limit. Hence, corrosion potential of passive steel, if in alkaline CSRE, is determined by the availability of oxygen at the surface of the rebars.

Although readings were taken over $24 \mathrm{~h}$, only dry and 1-h immersion measurements are presented in Fig. 8: corrosion potential dropped significantly in the first hour while immersed (as observed in Fig. 9(i) and (ii) insets), after which potential became more stable.

\subsubsection{Extended immersion and desorption testing}

At the completion of the 6th wetting and drying cycle (i.e. that which commenced at 25 weeks), reinforced specimens were fully immersed in tap water until mass equilibrium was reached (taking roughly 3 days). Corrosion potential was measured during prolonged wetting and as samples reequilibrated to ambient conditions (Fig. 9). Steel embedded in CSRE made with CL and SM1 remained comfortably in the passive condition throughout testing while steel in the RCA mix approached but did not exceed the threshold value of $-200 \mathrm{mV}$ SCE. Only steel embedded in SM2

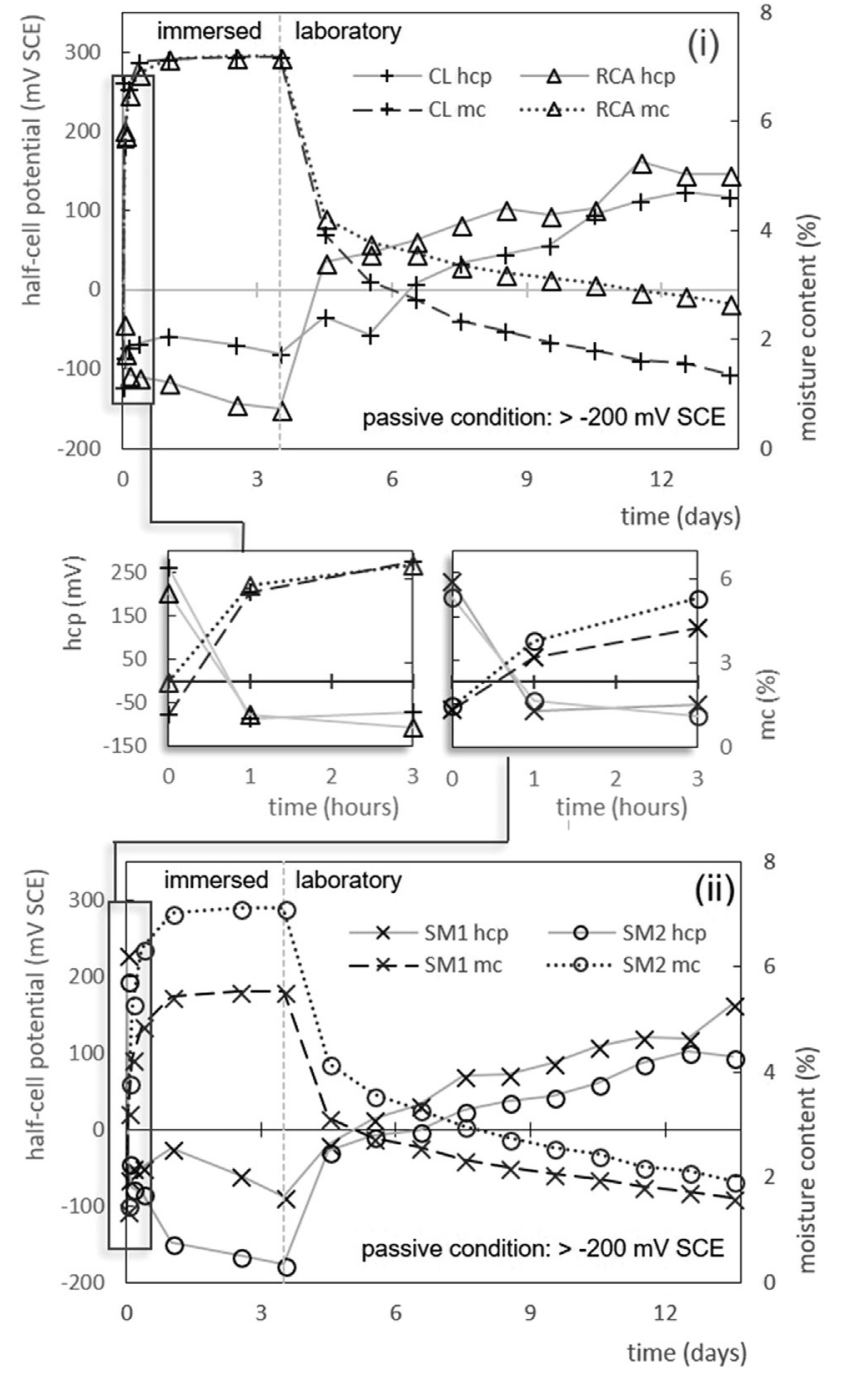

Fig. 9. Desorption following immersion to constant mass of: (i) CL and RCA, (ii) SM1 and SM2.

reached the corrosive limit on some occasions once immersed for at least $8 \mathrm{~h}$, however recovered to the passive state within one day of being removed from the water. Changes in HCP
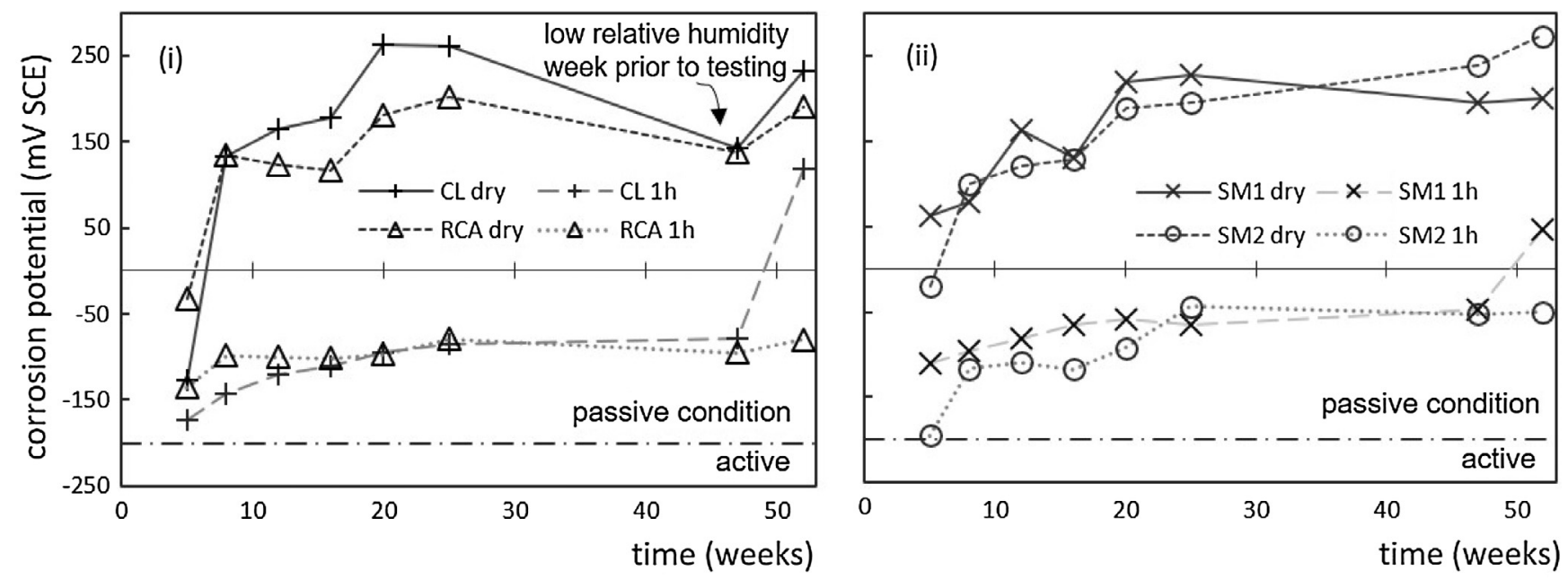

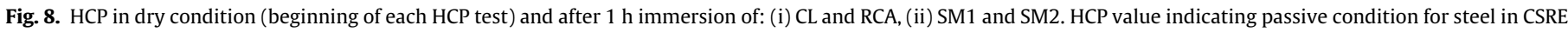
$(>-200 \mathrm{mV}$ SCE) is shown. 
measurements were strongly correlated with those in water content for all specimens; RCA and SM2, which absorbed the greatest amount of water, achieved the worst corrosion potential. Complete immersion is an extreme scenario for a rammed earth structure but, were it to occur (e.g. during flash flooding), the rapid desorption and increase in corrosion potential on removal from water shown in Fig. 9 suggest that the material would quickly recover (noting that results here do not account for other potentiallynegative effects of submergence, for example slaking).

\subsubsection{High humidity testing}

HCP results for specimens exposed to high humidity conditions following desorption testing (i.e. on reaching week 30 in Table 2) are shown in Fig. 10. HCP testing was completed until equilibrium with the high humidity air was reached, whereupon specimens were re-exposed to the lower humidity (ambient laboratory) conditions. Although corrosion potential dropped significantly (around $200 \mathrm{mV}$ ) on exposure to high air humidity, all specimens remained in the passive state throughout equilibration. Corrosion potential increased sharply on re-exposure to laboratory conditions, varying with the inverse of humidity as indicated in Fig. 10.

\subsubsection{Simulated rainfall}

$\mathrm{HCP}$ results for specimens exposed to water on one side only (at 44 weeks, i.e. after completion of high humidity testing) are shown in Fig. 11. The amounts of water added to simulate July 2016 rainfall in Perth are also given. As for fully immersed $(1 \mathrm{~h})$, extended immersion (3d) and high-humidity specimens, HCP reduced on wetting, but all specimens remained in passive condition at all times.

All specimens absorbed the full amount of water during the first 2 days' exposure except for SM1, which had the lowest IRA value. Results presented in Fig. 12 indicate that SM1 could absorb up to $77 \mathrm{~g}$ in $72 \mathrm{~h}$ : a greater amount than the applied $70.2 \mathrm{~g}$. That SM1 could not fully absorb this amount was due to periodic exposure, rather than the instantaneous (and so maximum) exposure used for IRA testing.

\subsection{Moisture content correlation}

The experiments described above indicated a relationship between HCP and specimen water content. Corrosion potential values and water contents from all HCP tests are shown in Fig. 13 (each soil mix separately) and Fig. 14 (all soil mixes

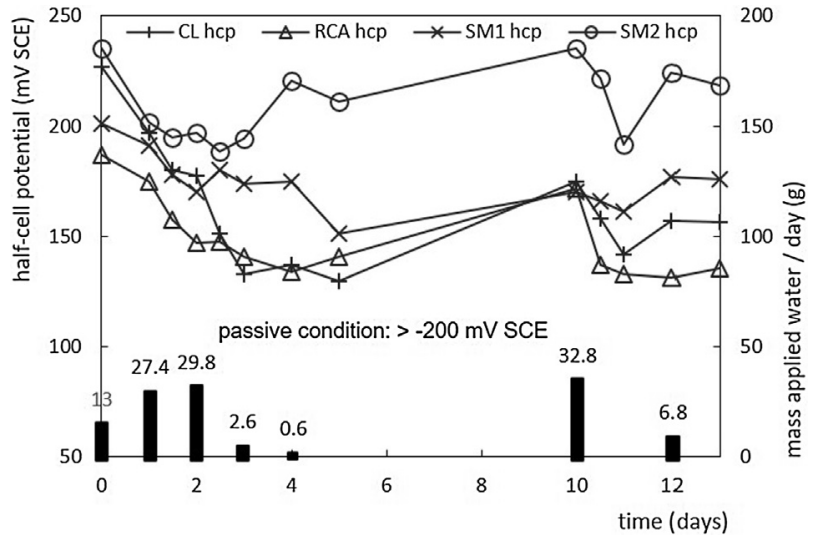

Fig. 11. HCP testing and simultaneous rain simulation.

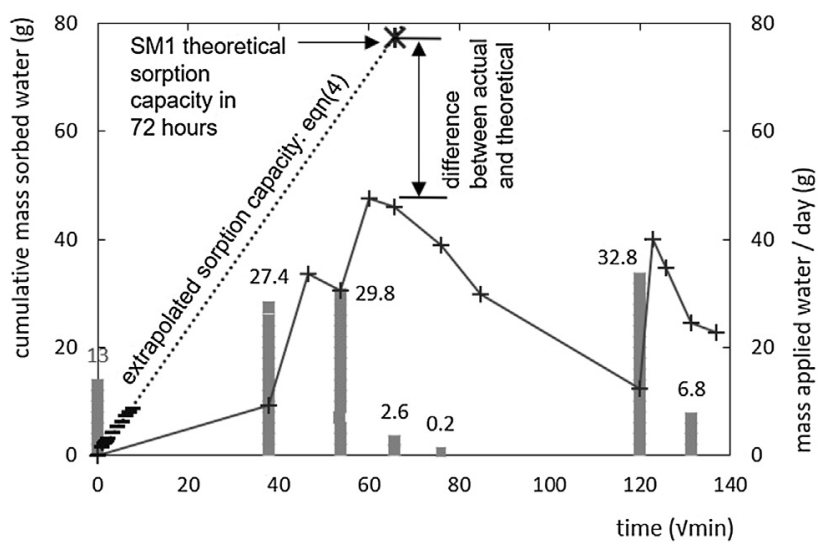

Fig. 12. SM1 theoretical sorption potential, applied water and actual sorbed mass.

combined). As shown, there is an influence of moisture content of CSRE on HCP measurement, regardless of environment and material. For CSRE in highest moist conditions, the diminished supply of oxygen to the surface of steel can bring the potential down to more negative value. However, all CSRE specimens tested were comfortably more positive than the $-200 \mathrm{mV}$ SCE corrosion limit in dry ambient laboratory conditions (Fig. 8), in the humidity room (Fig. 10) and during simulated rainfall HCP testing (Fig. 11) implying a negligible corrosion rate in each of these environments [25].

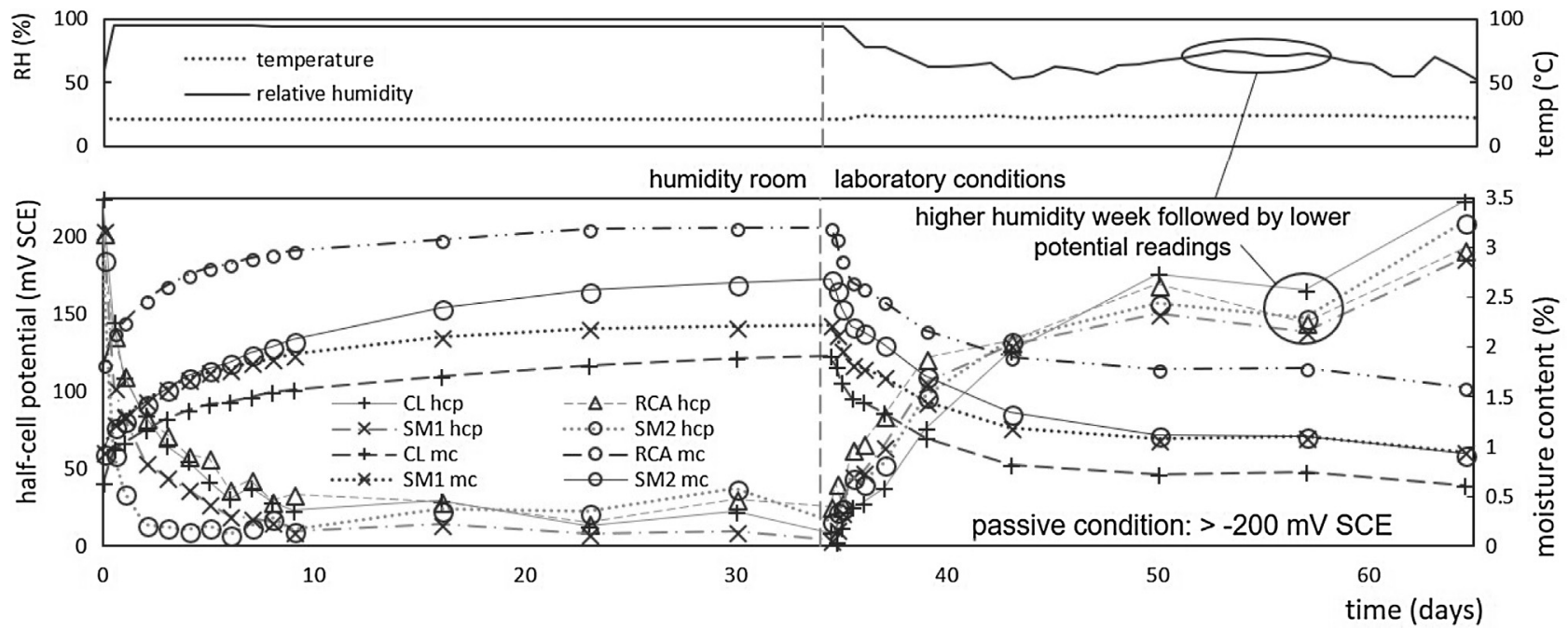

Fig. 10. HCP testing in high-humidity environment and re-equilibration to laboratory conditions. 

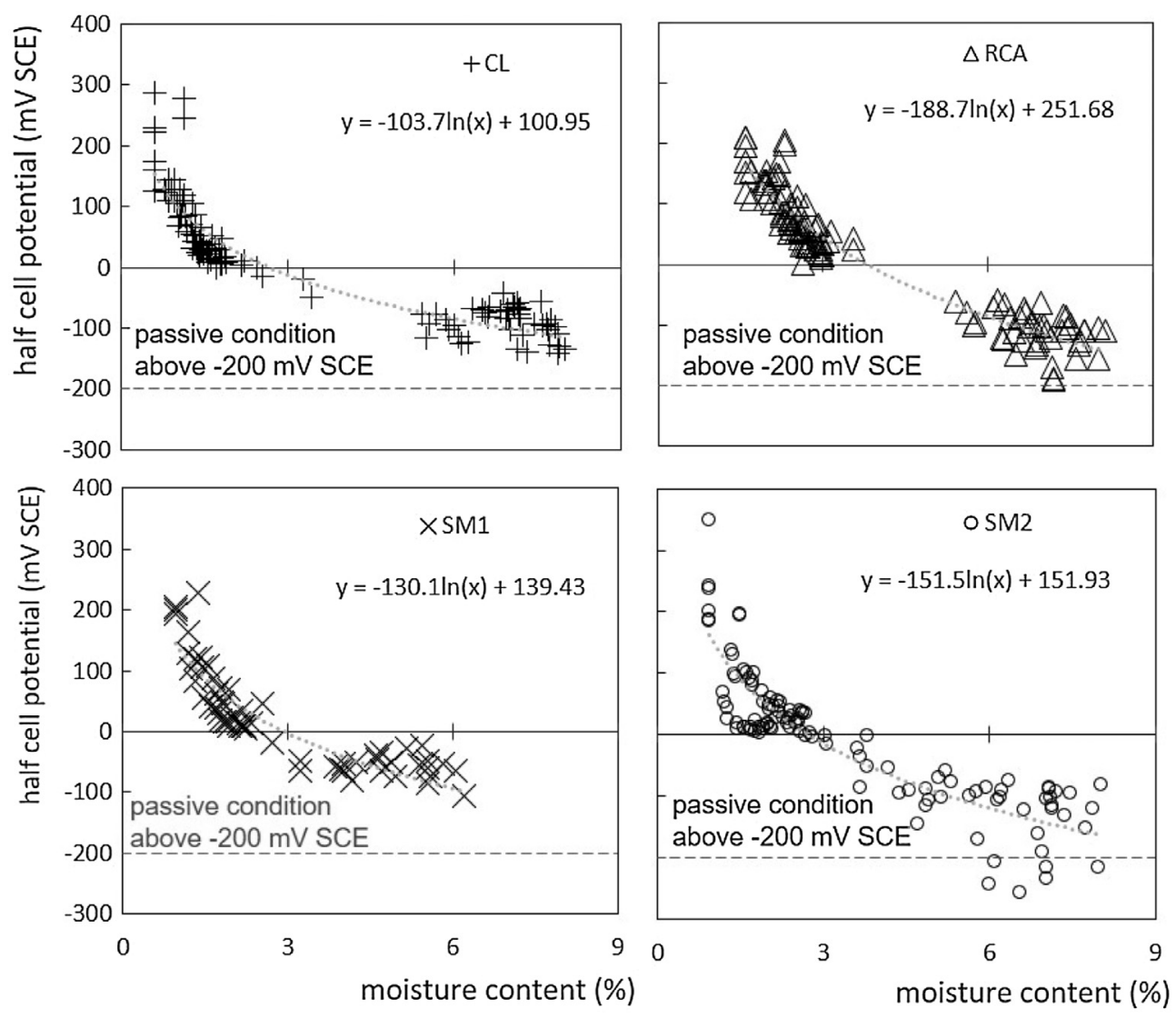

Fig. 13. HCP vs moisture content for CL (i), RCA (ii), SM1 (iii) and SM2 (iv) specimens in various environments.

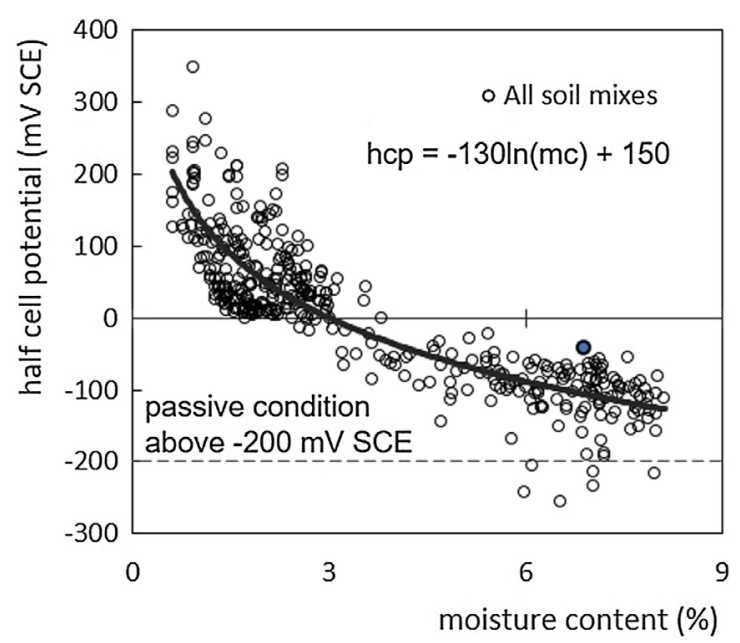

Fig. 14. HCP vs moisture content for all soil mixes in various environments.

During immersed testing, most specimens remained above -200 $\mathrm{mV}$ SCE throughout confirming that moisture content cannot change the corrosion behaviour of steel during initiation phase. Only SM2 readings dropped below $-200 \mathrm{mV}$ SCE on a few occasions (shown in Fig. 13(iv)) and only once specimens had a moisture content greater than $6 \%$, having been immersed in tap water for a minimum of $8 \mathrm{~h}$ : a highly unlikely scenario for a rammed earth structure. Local groundwater level and other potential causes of long-term wetting should be considered in design, particularly if considering a base soil high in clay. The corrosion potentials below $-200 \mathrm{mV}$ of SM2 specimen could be associated with local loss of the passive condition of steel bar; Fig. 13(iv) shows that corrosion was activated on SM2 specimens only in highly moist conditions.

For those results collated in Fig. 14, the relationship between moisture content and HCP can be described as

$H C P \approx-130 \ln (m c)+150$

Using Eq. (5), a moisture content of $15 \%$ would be required for HCP to drop below $-200 \mathrm{mV}$ SCE. Consulting the 30-week available pore volume data given in Table 1, SM1 will never reach the corrosive limit even at saturation, demonstrating that as long as CSRE is alkaline and without chlorides on the steel surface, moisture content doesn't affect the passive state. SM2 becomes more negative than $-200 \mathrm{mV}$ SCE once at $88 \%$ saturation probably because steel bars present a localised breakdown of the passive film.

These results suggest that the tested CSRE mixes provide corrosion protection to the steel reinforcement so long as the material remains alkaline (in the absence of chlorides). Once steel is depassivated by carbonation or chlorides, the corrosion potential behaviour depends on the moisture content of CSRE.

\subsection{Destructive testing}

Twelve months post-manufacture, one specimen of each soil mix except SM1 was broken in half to allow visual inspection of the rebar. As shown in Fig. 13, throughout testing in all environments, RCA and CL specimens maintained a corrosion potential more positive than $-200 \mathrm{mV}$ SCE at all times whereas SM2 dropped below this (i.e. to potentials at which corrosion activity may occur) on several occasions. These results were supported by the destructive testing shown in Fig. 15: the final conditions of the extracted rebar matched those surmised from HCP testing 


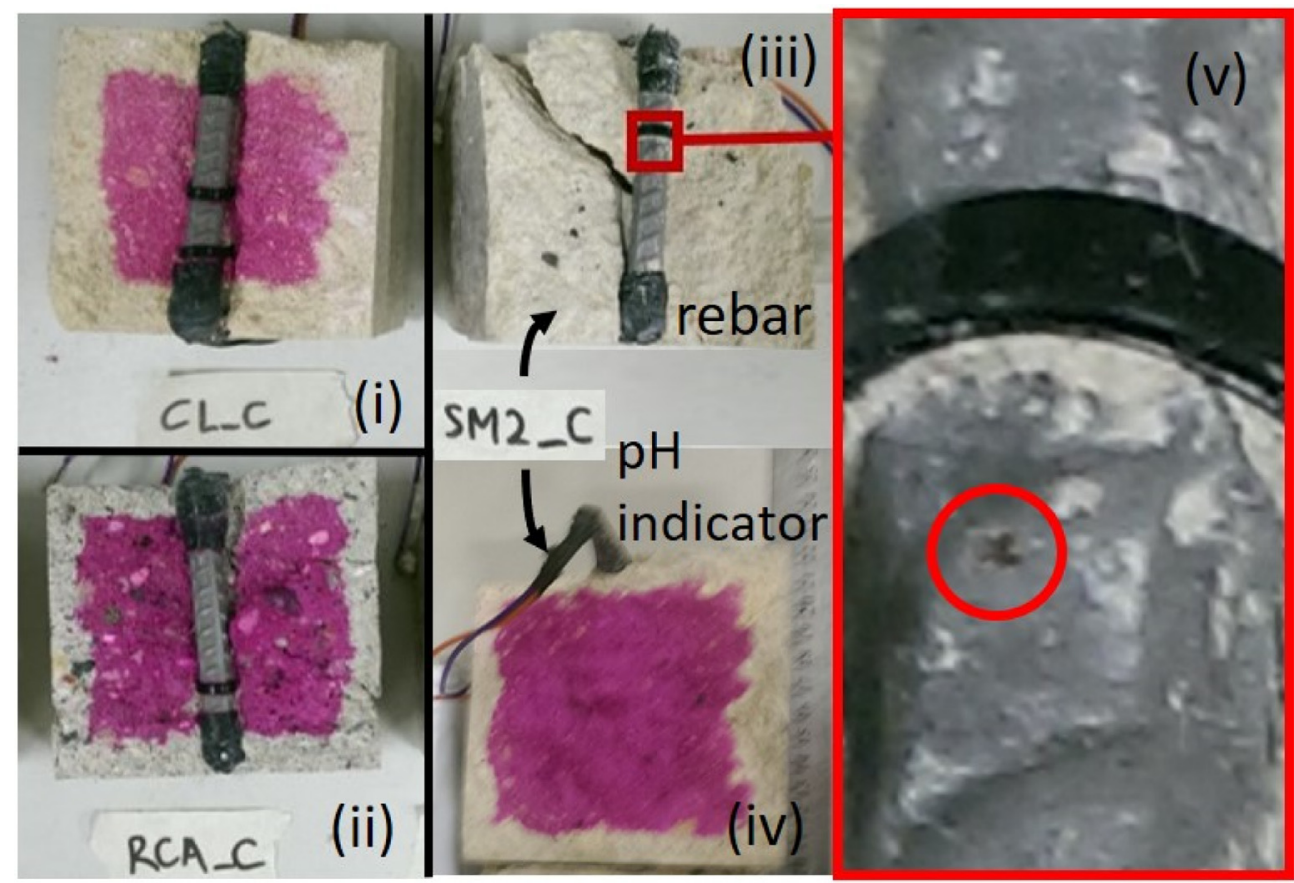

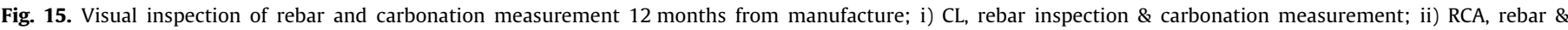
carbonation; iii) SM2, rebar only (no pH indicator); iv) SM2, carbonation only (with pH indicator); v) SM2, inset showing fleck of rust.

- CL and RCA showed no sign of corrosion while SM2 had one fleck of rust visible. This suggests that the value of $-200 \mathrm{mV}$ SCE was a reasonable indicator of the loss of passive state for the tested CSRE specimens. However, further investigation considering a large exposition time and a greater number of specimens could be of use.

12-Month carbonation testing (shown in Fig. 15) confirms that the reinforced specimens remained in the passive condition throughout testing. Work assessing corrosion behaviour of depassivated carbon steel in carbonated CSRE is ongoing.

\section{Conclusions}

Steel reinforcement is an example of a modern adaptation to traditional rammed earth building techniques. However, little is known about how steel in such an environment interacts with its surroundings. This study assessed the ability of a range of CSRE mixes to provide corrosion protection to carbon steel, using testing methods described in ASTM C876-91 [20] and a corrosion potential lower limit of $-200 \mathrm{mV}$ SCE [25].

$\mathrm{pH}$ of the CSRE mixes studied in this work were all sufficiently alkaline to provide the appropriate environment for passivation of steel reinforcement; in fact, the hydrated cement paste of CSRE is initially alkaline in the same way as for conventional concrete. However, the resistance to carbonation of CSRE is also of primary importance in relation to the protection of embedded steel. This experimental study has shown that for typical cover depths, carbonation would most likely have reached the reinforcement within approximately $5-15$ years ( $50 \mathrm{~mm}$ cover) or $30-75$ years $(150 \mathrm{~mm}$ cover) depending on the CSRE mix considered. Therefore, although the initial CSRE environments tested may be adequate for passivation, rebar will be depassivated within the design life span. Specimens compacted to MDD performed better than those compacted to a lower density, given which, a target density for site work should be specified and monitored if particular characteristics are required.

A correlation between corrosion potential and moisture content was found, regardless of environment and soil mix. For CSRE in highest moist conditions, the diminished supply of oxygen to the surface of steel brought the potential down to a more negative value. However, all CSRE specimens tested were comfortably more positive than the $-200 \mathrm{mV} \mathrm{SCE}$ corrosion limit both in dry ambient laboratory conditions and in moist conditions, implying a negligible corrosion rate in each of these environments. During immersed testing, most specimens remained above $-200 \mathrm{mV}$ SCE throughout, confirming that moisture content cannot influence the corrosion behaviour of steel in CSRE that is both alkaline and without chlorides near to the steel surface; thus, the moisture condition doesn't affect passive state. Only for steel embedded in SM2 specimens, a corrosion potential more negative than $-200 \mathrm{mV}$ SCE was measured in immersion conditions, most likely because steel bars had a localised breakdown of the passive film as confirmed from the small rust spot observed by destructive testing. However, a rapid desorption was found to be typical of the CSRE specimens, meaning the material would dry quickly if exposed to a temporarily detrimental environment such as heavy rain or flooding. Given rapid desaturation, it is likely that corrosion propagation of steel in SM2 specimens would remain negligible. Destructive tests of all other reinforcing bars show no sign of corrosion due to their being protected in alkaline CSRE.

These results suggest that the tested CSRE mixes provide corrosion protection to the steel reinforcement so long as the material remains alkaline (in the absence of chlorides). Once steel is depassivated by carbonation or chlorides, the corrosion potential behaviour depends on the moisture content of CSRE.

As behaviour varied little between the four tested soil mixes (of varying granularity), it is reasonable to expect that findings presented here also apply to other soil mixes stabilised with $10 \%$ cement. However, as SM2 performed most poorly, the performance of mixes manufactured with base soils high in clay ( $>15 \%)$ may be worthy of further investigation.

\section{Conflict of interest}

The authors have no conflicts of interest to declare. The work is original and is not under consideration by any other journal or conference. 


\section{Acknowledgements}

The authors acknowledge Prof Luca Bertolini, who unfortunately passed away last year, for his extensive contributions to understanding of durability of steel in concrete and its preservation. In particular, Prof Bertolini was instrumental in planning the research work presented in this paper.

The authors thank Grazia Orfeo, Emanuele Lucianò and Luke Medigovich for their contributions to the laboratory work. We also thank A/Prof Sarah Lumley and Daniel Sly for proofreading.

\section{Funding}

This study was supported by the University of Western Australia Hackett Postgraduate Research Scholarship, Australia and Australian Research Council Linkage Project [grant number LP1101000251], Australia.

\section{Competing interests}

The authors have no competing interests to declare.

\section{References}

[1] NZS 4298:1998, Materials and Workmanship for Earth Buildings [Building Code Compliance Document E2 (AS2)], Stand. New Zealand, Wellington, NZ 1998, p. 91.

[2] P.J. Walker, S. Dobson, Pullout test on deformed and plain rebars in cementstabilized rammed earth, J. Mater. Civ. Eng. 13 (2001) 291-297, https://doi.org 10.1061/(ASCE)0899-1561(2001) 13:4(291)

[3] K. Tuutti, Corrosion of Steel in Concrete, Stockholm, 1982.

[4] C.T.S. Beckett, D. Ciancio, Durability of cement-stabilised rammed earth: a case study in Western Australia, Aust. J. Civ. Eng. (2015), https://doi.org/10.1080/ 14488353.2015.1092671.

[5] L. Bertolini, B. Elsener, P. Pedeferri, E. Redaelli, R. Polder, Corrosion of Steel in Concrete: Prevention, Diagnosis, Repair, second ed., Wiley-VCH Verlag GmbH \& Co. KGaA, Boschstr. 12, 69469 Weinheim, Germany, 2013.

[6] C. Beckett, D. Ciancio, Effect of compaction water content on the strength of cement-stabilized rammed earth materials, Can. Geotechnol. J. 51 (2014) 583590, https://doi.org/10.1139/cgj-2013-0339.

[7] AS 1289.3.6.1-2009, Methods of Testing Soils for Engineering Purposes: Determination of the Particle Size Distribution of a Soil - Standard Method of Analysis by Sieving, Stand. Aust. Int. Ltd, Sydney, 2009.

[8] A. Arrigoni, C. Beckett, D. Ciancio, G. Dotelli, Life cycle analysis of environmental impact vs. durability of stabilised rammed earth, Constr. Build. Mater. 142 (2017) 128-136, https://doi.org/10.1016/ j.conbuildmat.2017.03.066.

[9] H.E. Acosta-Martinez, S.M. Gourvenec, One-dimensional Consolidation Tests on Kaolin Clay, Research Report GEO: 06385, Centre for Offshore Foundations Systems, School of Civil and Resource Engineering, The University of Western Australia, Perth, Australia, 2006.

[10] M.R. Hall, R. Lindsay, M. Krayenhoff (Eds.), Modern Earth Buildings, Woodhead Publishing, Cambridge, UK, 2012.
[11] AS 1289.5.2.1-2003, Methods of Testing Soils for Engineering Purposes, Method 5.2.1: Soil Compaction and Density Tests - Determination of the Dry Density/Moisture Content Relation of a Soil Using Modified Compactive Effort, Stand. Aust. Int. Ltd, Sydney, 2003.

[12] S. Burroughs, Recommendations for the selection, stabilization, and compaction of soil for rammed earth wall construction, J. Green Build. 5 (2010) 101-114.

[13] AS 5101.4-2008, Methods for Preparation and Testing of Stabilized Materials - Method 4: Unconfined Compressive Strength of Compacted Materials, Stand. Aust. Int. Ltd, Sydney, 2008.

[14] J.L. Eades, R.E. Grim, A quick test to determine lime requirements for lime stabilisation, in: Proc. 45th Annu. Meet. Comm. Lime Lime-Fly Ash Stabilisation, 1966, pp. 61-72.

[15] I.S. EN 13295:2004, Products and Systems for the Protection and Repair of Concrete Structures - Test Methods - Determination of Resistance to Carbonation, Natl. Stand. Auth. Ireland, Dublin, Ireland, 2004.

[16] M. Hall, Y. Djerbib, Moisture ingress in rammed earth: Part 2 - the effect of soil particle-size distribution on the absorption of static pressure-driven water, Constr. Build. Mater. 20 (2006) 374-383, https://doi.org/10.1016/ j.conbuildmat.2005.01.035.

[17] AS/NZS 4456.17:2003, Masonry Units, Segmental Pavers and Flags - Methods of Test, Method 17: Determining Initial Rate of Absorption (suction), Stand. Aust. Int. Ltd, Sydney, 2003.

[18] M.R. Hall, Y. Djerbib, Moisture ingress in rammed earth: Part 1 - the effect of soil particle-size distribution on the rate of capillary suction, Constr. Build. Mater. $18 \quad$ (2004) 269-280, https://doi.org/10.1016/ j.conbuildmat.2003.11.002.

[19] D. Ciancio, C.T.S. Beckett, J.A.H. Carraro, Optimum lime content identification for lime-stabilised rammed earth, Constr. Build. Mater. 53 (2014) 59-65, https://doi.org/10.1016/j.conbuildmat.2013.11.077.

[20] ASTM C876-91, Standard Test Method for Half-Cell Potentials of Uncoated Reinforcing Steel in Concrete, ASTM Int., West Conshohocken, USA, 1991, Doi: 10.1520/C0876-09.2.

[21] G.G. Clemeña, Benefits of Measuring Half-Cell Potentials and Rebar Corrosion Rates in Condition Surveys of Concrete Bridge Decks, 1992.

[22] V. Leelalerkiet, J.W. Kyung, M. Ohtsu, M. Yokota, Analysis of half-cell potential measurement for corrosion of reinforced concrete, Constr. Build. Mater. 18 (2004) 155-162, https://doi.org/10.1016/j.conbuildmat.2003.10.004.

[23] Bureau of Meteorology, Climate Data Online, (2017). http://www.bom.gov. au/climate/data/ (accessed February 10, 2017).

[24] C. Christodoulou, Electrochemical treatments of corroded reinforcement in concrete, in: .G. Alexander, H. Beushausen, F. Dehn, P. Moyo (Eds.), Proc. 2nd Int. Conf. Concr. Repair, Rehabil. Retrofit. ICCRRR-2, CRC Press, Taylor \& Francis Group, Cape Town, South Africa, 2009.

[25] F. Yang, Corrosion Protection of Steel Embedded in New Sustainable Cementitious Materials, Department of Chemistry, Materials and Chemical Engineering of Politecnico di Milano, 2017.

[26] I. Yoon, O. Copuroglu, K.-B. Park, Effect of global climatic change on carbonation progress of concrete, Atmos. Environ. 41 (2007) 7274-7285, https://doi.org/10.1016/j.atmosenv.2007.05.028.

[27] C.T.S. Beckett, R. Cardell-Oliver, D. Ciancio, C. Huebner, Measured and simulated thermal behaviour in rammed earth houses in a hot-arid climate, Part B: Comfort, J. Build. Eng. 13 (2017) 146-158, https://doi.org/10.1016/j. jobe.2017.07.013.

[28] M. Byrami, Rate of Absorption of Water by Litecrete Lightweight Concrete and Normal Concrete, Auckland, New Zealand, 2006.

[29] NZS 4299:1998, Earth Buildings Not Requiring Specific Design, Stand. New Zealand, Wellington, NZ, 1998. 